\title{
An Experimental Research on the Vibration of Surface-Textured Journal Bearings
}

\author{
Jian Dong, Xiaojing Wang, Jin Zhang, Xiaoqing Xiang, Zhou Nie, and Jiexi Shen
}

School of Mechanical Engineering and Automation, Shanghai University, Shanghai, China

Correspondence should be addressed to Xiaojing Wang; wangxjshu@163.com

Received 19 February 2017; Revised 4 April 2017; Accepted 9 April 2017; Published 9 May 2017

Academic Editor: Marco Alfano

Copyright (C) 2017 Jian Dong et al. This is an open access article distributed under the Creative Commons Attribution License, which permits unrestricted use, distribution, and reproduction in any medium, provided the original work is properly cited.

\begin{abstract}
Growing attention has been paid to surface texture owing to its significance in bearing lubrication, load capacity, and wear resistance. In this paper, research emphasis is placed on the influence of texture distributions on bearing vibration and rotor stability. With microfabrication techniques, three kinds of textures configurations $\left(0-90^{\circ}\right.$ partial distribution, $0-160^{\circ}$ partial distribution, and $0-160^{\circ}$ full distribution) are designed and applied on the lower pad surface. The experiment of journal bearings is carried out. The experiment results show that there is a significant decrease in acceleration amplitude of the textured bearings compared to nontextured bearings. Furthermore, the $0-160^{\circ}$ partially distributed journal bearings have better vibration damping effect than another two kinds of textures, which can be verified by the shaft center orbits, Fourier spectrums, and waterfall plots.
\end{abstract}

\section{Introduction}

Journal bearings have been widely used in turbomachinery and power generator. With the high rotating speed, vibration and stability of rotor-bearing systems have an increasingly important impact on the performance of machineries and equipment. The influence of surface texture on journal bearing operating performance has attracted more and more attention. A lot of researches [1] have been done to investigate the relationship between surface profile and bearing hydrodynamic lubrication performance. To begin with, Kumada [2] compared tribological properties between the normal plain bearings and microgrooved bearings developed for the use as crankshaft and connecting-rod bearings in gasoline engines. It was found that the microgrooved bearings show smaller temperature rises by 10-20 percent over the whole rotational speed range. Sahlin et al. [3] also introduced a microgroove on one of the two parallel surfaces. It was shown that friction force decreases with deeper and wider grooves and load carrying capacity increases with Reynolds number and groove width. Cupillard et al. [4] studied the effect of surface texture on bearing friction and load carrying capacity using computational fluid dynamics. Reduction in friction coefficient was observed for deep dimples located in the maximum pressure region at high eccentricity ratios and for shallow dimples located just downstream of the maximum film at low eccentricity ratio. Yong and Balendra [5] also used CFD method to analyze the lubrication behaviors of journal bearings with dimples. The introduction of dimple was beneficial to lubrication performance in terms of friction force compared to the smooth plate sliding, even when there was some loss of load capacity. But the profile of dimple had little effect on the friction force and friction coefficient. Nanbu et al. [6] investigated the effects of texture bottom shape and surface relative motion on lubrication enhancement. The results suggested that the bottom shapes involving a microwedge or a microstep bearing tend to yield thicker films and textures on the faster moving surface offer stronger film thickness enhancement. Sinanoğlu et al. [7, 8] presented an analysis of the pressure development of journal bearing in a various shaft surface texture. The surface of the shafts had been in two types-smooth, that is, without profiles, and with profiles, that is, trapezoidal and saw. The trapezoidal shaft can carry more loads than the saw shaft. In addition, the shaft that has the same profile but a lower profile height and pitch value can carry fewer loads. Theoretical and experimental analysis of a laser-textured thrust bearing had been done by Marian et al. $[9,10]$ and a good agreement was 
TABLE 1: Parameters of the rotor-bearing system.

\begin{tabular}{lcccccccc}
\hline $\begin{array}{l}\text { Mass of disc } \\
(\mathrm{kg})\end{array}$ & $\begin{array}{c}\text { Mass of shaft } \\
(\mathrm{kg})\end{array}$ & $\begin{array}{c}\text { Bearing } \\
\text { diameter } \\
(\mathrm{mm})\end{array}$ & $\begin{array}{c}\text { Bearing } \\
\text { length } \\
(\mathrm{mm})\end{array}$ & $\begin{array}{c}\text { Radial } \\
\text { clearance } \\
(\mu \mathrm{m})\end{array}$ & $\begin{array}{c}\text { Oil viscosity } \\
(\mathrm{Pa} \cdot \mathrm{s})\end{array}$ & $\begin{array}{c}\text { Supply oil } \\
\text { temperature } \\
\left({ }^{\circ} \mathrm{C}\right)\end{array}$ & $\begin{array}{c}\text { Supply oil } \\
\text { pressure } \\
\text { MPa }\end{array}$ & $\begin{array}{c}\text { Oil type } \\
0.45\end{array}$ \\
\hline & 0.1 & 24.73 & 24 & 25 & 0.039 & 35 & 0.1 & ISO-VG32 \\
\hline
\end{tabular}

found between the theoretical model and the experimental data for the two measured parameters (fluid film thickness and friction torque).

Besides, Ausas et al. [11] showed that, in the presence of microtextured bearing surfaces, Reynolds' model largely underestimates the cavitated area, resulting in an overestimation of the friction torque, while a mass-conserving cavitation model was recommended when evaluating the performance of microtextured bearings. A physical model for a bearing with a series of semispherical dimples was modeled by Meng and Yang [12]. In the paper, the cavitation mechanisms at different positions and sizes of the dimple were studied with CFD method.

In addition, laser surface-textured parallel thrust bearing and journal bearing were researched, respectively, by Brizmer and Kligerman [13] and Brizmer et al. [14], and the optimum parameters of the dimples and favorable LST mode for maximum load capacity had been found. Tala-Ighil et al. [15] have studied the effect of textured area on the performances of a hydrodynamic journal bearing. 25 different configurations of texture were presented in this paper. The result showed that full texturing appears ineffective to generate hydrodynamic load capacity in the contact by the cavitation effects. However, partial texturing can generate hydrodynamic lift in bearing when the texture is located in the declining part of the contact pressure field.

Furthermore, a review of surface texturing on different bearing couples has been presented [16] by Ibatan et al., who illustrate that surface engineering has a great potential in improving the tribological performance of bearings in varying applications and operating conditions. The potential of LST in tribological components like mechanical seals, piston rings, and thrust bearings is also proposed by Etsion [17].

As mentioned above, many researchers have paid efforts to investigate the static characteristics, such as friction coefficient, cavitation model, pressure distribution, and load capacity. But only a few people conducted study on dynamic characteristics of bearings with various textures. In the paper [18], two more structure patterns (i.e., checkerboard and sinusoidal dimples) have been studied by Tønder. Except load capacity and coefficient of friction, stiffness and damping are also studied. The dynamic coefficients of cylindrical textured journal bearing are also presented by Ganji and Kakoty [19]. It was found that increase in texture depth improves the stability of hydrodynamic journal bearing. The effect of texture portion on stability was pronounced and the maximum stability was obtained at $50 \%$ texture portion for their research conditions. Dadouche et al. [20] carried out an experimental analysis to study the effect of texture on the steady-state and dynamic properties of plain journal bearings. Four textured bearings with different dimple densities were tested in addition to a smooth surface bearing. They found that medium-textured surface bearing represents the optimum dimple-density as it leads to a stable bearing and increases both bearing direct stiffness coefficients, but textured journal bearings run hotter (about 6 to $8^{\circ} \mathrm{C}$ ) than plain smooth surface bearings. After the work, Dadouche and Conlon [21] also conducted an experiment to investigate the effect of surface texturing on the steady-state performance characteristics of highly loaded journal bearings lubricated with a contaminated lubricant. By analyzing the waterfall plots, overall vibration measurements, and posttest inspection of bearing, they concluded that lightly textured bearings show exceptional performance in terms of contamination tolerance.

In this paper, deterministic surface texture is designed and machined to analyze the influence of textures location on bearing vibration and stability.

\section{Experimental Procedure}

2.1. Experimental Apparatus. The test rig, which can test vibration and stability of rotor-journal bearing system, is shown in Figure 1(a). The main shaft, which is supported by a pair of test bearings, is driven by a speed-adjustable motor through a flexible coupling. An oil supply system is available to provide a steady flow of lubricating oil for the testing system while the oil sink mounted on the T-slot cast iron base can reserve the lubricants. When the shaft starts rotating, hydrodynamic film is formed between test bearings and the rotating journals. Eddy current sensors (TR81 model: 810503; sensitivity: $( \pm 5 \%) 5 \mathrm{v} / \mathrm{mm})$ are installed perpendicular to each other to measure displacements of the shaft center. In addition, accelerometers (PCB model: 352C03; sensitivity: $( \pm 10 \%) 10 \mathrm{mV} / \mathrm{g}$ ) are fixed horizontally and vertically on the bearing base by glue for testing vibration level. Their installation positions are, respectively, shown in Figures 1(b) and 1(c). The vibration data of the bearings will be eventually obtained by signal sampling and processing system from Bruel \& Kjaer PULSE.

The same geometrical parameters studied by Zhan et al. [22] are used here for the experiment. All bearings were lubricated using ISO-VG32 grade turbine oil at a supply pressure of $0.1 \mathrm{MPa}$. The lubricant was fed to the bearing bushing from the top of bearing housing through a radial hole at a constant temperature of $35^{\circ} \mathrm{C}$. Some important parameters of the rotor-bearing system are presented in Table 1.

2.2. Texture Processing. Experiments are conducted to find out which kind of textures behaves better in several 


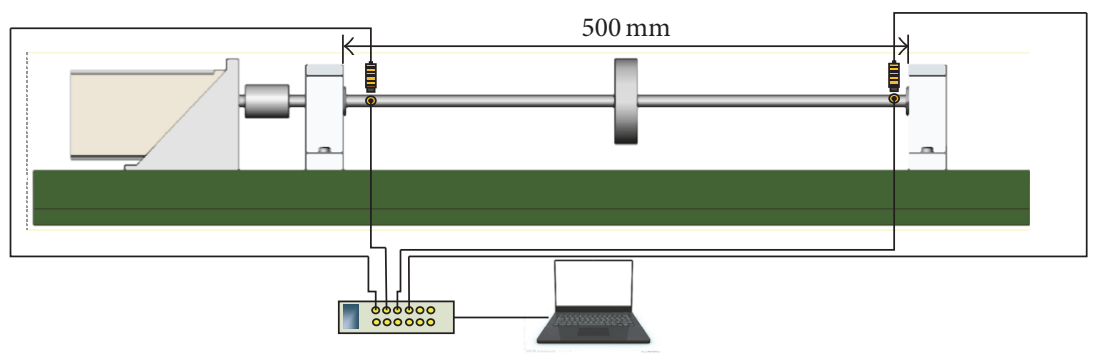

(a)

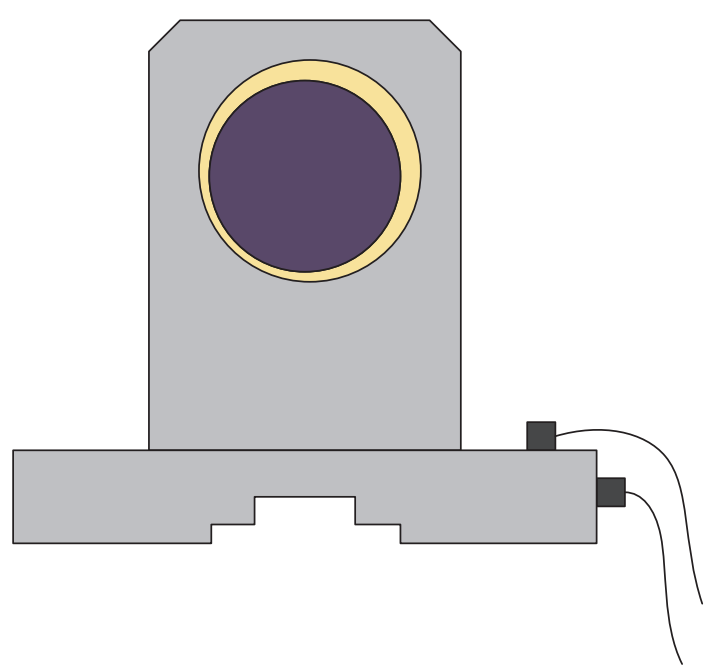

(b)

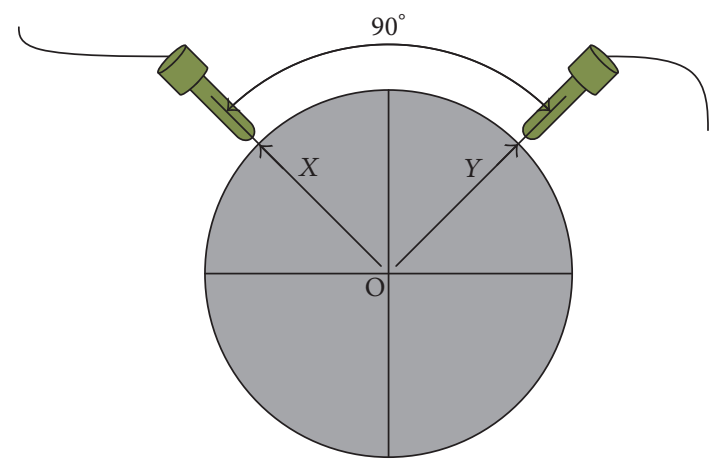

(c)

FIGURE 1: Schematic view of the test rig: (a) general view; (b) accelerometers installation; (c) eddy current sensors installation.

TABLE 2: Textures configurations on the bearing surface.

\begin{tabular}{lcccc}
\hline Parameter & Case 1 & Case 2 & Case 3 & Case 4 \\
\hline Depth $(\mu \mathrm{m})$ & - & 30 & 30 & 30 \\
Width $(\mu \mathrm{m})$ & - & 500 & 500 & 500 \\
Length $(\mu \mathrm{m})$ & - & 700 & 700 & 700 \\
Area ratio $(\%)$ & - & 20 & 35 & 44 \\
$\theta\left(^{\circ}\right)$ & - & 90 & 160 & 160 \\
Density $(\%)$ & - & 32 & 32 & 32 \\
\hline
\end{tabular}

configurations mentioned by Tala-Ighil et al. [15]. It is well accepted that dimple aspect ratio, texture location, and density are the most important design parameters for textured contacts. Therefore, most studies have been contributed to finding optimal values for those parameters. In this paper, lower pad surface is textured with rectangular dimples by laser processing. Laser texturing provides a relatively cheap and rapid method to create textured surface; Figure 2 briefly shows a schematic diagram of the partially textured journal bearing with rectangular dimples. For textured and nontextured bearings, the inner diameter and length of each bearing bushing are $24.73 \mathrm{~mm}$ and $24 \mathrm{~mm}$ and radial clearance is $25 \mu \mathrm{m}$, which has been shown in Table 1. Figure 3 displays the magnified view of the rectangular dimples. Three kinds of texture distribution are considered: as Table 2 shows,
Case 1 means no texture is machined on the bearing surface; Case 2 represents a $0-90^{\circ}$ partial distribution along the semicircle; Case 3 represents a $0-160^{\circ}$ partial distribution; Case 4 represents a $0-160^{\circ}$ full distribution. Here, both start angle and end angle of the texture location are shown in Figure 2. In the present work, only one depth is considered, and average depth and width of the three cases are $30 \mu \mathrm{m}$ and $500 \mu \mathrm{m}$. Area ratio is computed in the form of textured area over total superficial area. All the cases of textures area arrangements on the developed surface of the lower pad are illustrated in Figure 4. Besides, texture density in a cell is $32 \%$ (area of dimples of a cell/area of a cell); the cell is represented by a blue box in Figure 4 .

\section{Results and Discussion}

3.1. Experiment Results. The bearing housing vibration level is important for evaluation of machinery quality in the research of low noise machine. The rotor disturbance gives rise to transient change of oil film force; thus oil film transmits force to the bearing housing. It is worth mentioning here that the value of signals also includes vibrations generated due to the rotation of disk and the drive system in addition to the concentrated contacts induced vibrations. Figure 5 shows the acceleration amplitude of bearing housing in horizontal direction and vertical direction with increase of rotating speed. 


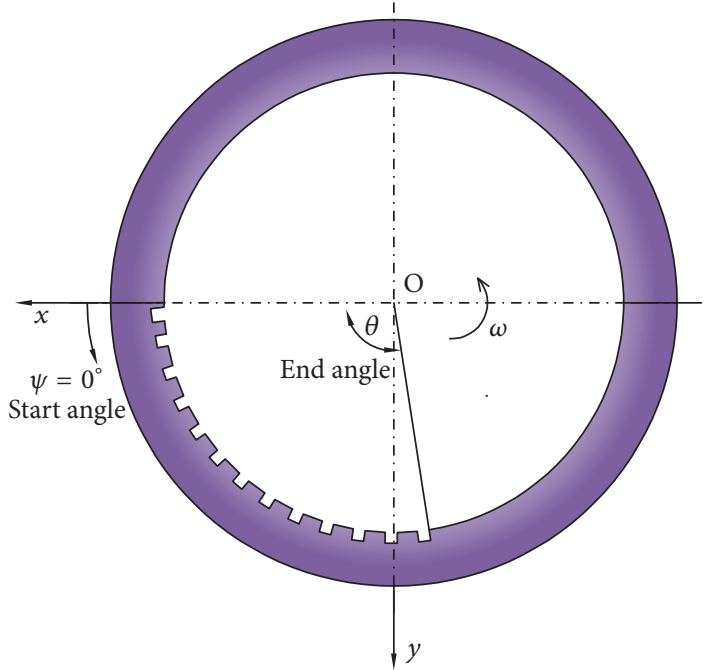

Figure 2: Partially textured journal bearing.

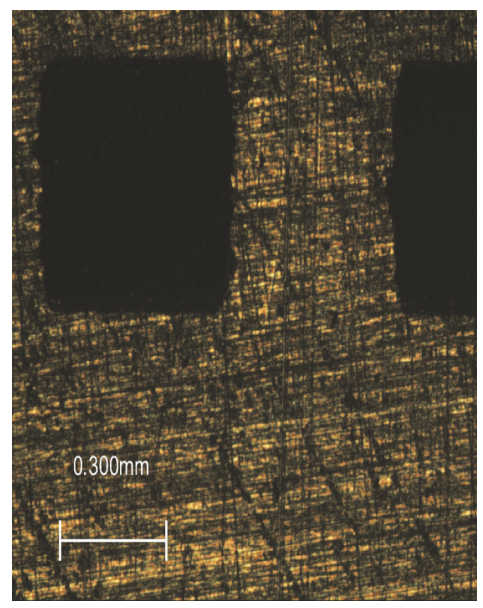

FIGURE 3: LST microsurface structure.

The acceleration is extracted as a sum value, whose frequency is between $10 \mathrm{~Hz}$ and $8000 \mathrm{~Hz}$. The rotor critical speed is $3600 \mathrm{r} / \mathrm{min}$ approximately, which is calculated by using transfer matrix method. It is easily found that when increasing shaft velocity from 0 to $3600 \mathrm{rpm}$, acceleration in both horizontal and vertical direction is increased continuously, and obviously a rapid rise begins at $2800 \mathrm{rpm}$. Furthermore, surface-textured bearings show noticeable damping effect compared to nontextured bearings. From Figure 5(a), a maximum acceleration difference of $5 \mathrm{~dB}$ has been found in horizontal direction. Besides, textured bearings with $0-160^{\circ}$ full distribution reduce vibration prominently at the speed $0 \sim 2800 \mathrm{rpm}$. However, when the rotation speed is greater than $2800 \mathrm{rpm}, 0-160^{\circ}$ partial distributed journal bearing contributes more than the others in vibration control; thus it can effectively counter force transferring to the bearing housing.
In order to further investigate the stability of journal bearings under specified rotating speed for different textures distribution, shaft center orbits are drawn and compared. To measure the rotor motion relative to the static equilibrium position, two eddy current transducers are needed to be installed perpendicular and coplanar to each other. A lowpass ellipse filter is designed to suppress harmonic noise in the signal processing. As shown in Figure 6, the results show that shaft center orbit of the bearings with $0-160^{\circ}$ partially distributed textures tends to be more flat than the others and area enclosed by the elliptical orbit is the minimum. The authors in [23] described that the destabilizing effect of cross coupling is directly proportional to the area of the whirl orbit, which can be written as follows:

$$
E_{\text {cyc }}=A\left(K_{x y}-K_{y x}\right) .
$$

In this equation, $A$ represents the area enclosed by the elliptical orbit while parameters $K_{x y}$ and $K_{y x}$ mean cross-coupled stiffness and $E_{\text {cyc }}$ represents energy per cycle imparted to the shaft [24]. To some extent, only lower bearing that is textured partially can alter the circular geometry, introducing asymmetry into the direct stiffness of oil film and resulting in smaller area and better stability. Therefore, in some way, $0-160^{\circ}$ partial distribution produces the minimum whirl energy in the three cases.

Fourier spectrum analysis is a tool of utmost importance in signal processing applications as well as a traditional method to study vibration signal, which is in terms of a spectrum of frequencies. While time-domain analysis shows how a signal changes over time, frequency-domain analysis shows how the signal's energy is distributed over a range of frequencies. Comparison of spectrums among three texture cases at three different rotating speeds is presented in Figure 7. Here the amplitude refers to the shaft center displacement in $y$ direction. From the graphs, the bearing textured $0-90^{\circ}$ partially shows largest displacement amplitude, while $0-160^{\circ}$ partially textured bearing shows the smallest one. Apparently, the journal bearing textured in $0-160^{\circ}$ partial distribution displays the best vibration control effect while the bearing with $0-90^{\circ}$ partial distribution is inferior to the others. The result proved that surface-textured journal bearing with $0-160^{\circ}$ partial distribution is the optimal texture configuration in the work condition.

To study the response of textured journal bearing system in the run-up process, waterfall plot is used to show how two-dimensional information changes over time or some other variable such as rpm, allowing the engineer to quickly view the entire frequency spectrum and the complete speed range. Here, the amplitude also refers to the shaft center displacement in y direction. Comparing the three waterfall plots in Figure 8, it is found that displacement amplitude of journal bearing with $0-90^{\circ}$ partial texture distribution is almost the largest, which is nearly twice that of bearing with $0-160^{\circ}$ partial texture distribution. Besides, according to order analysis, bearing of $0-160^{\circ}$ full texture distribution shows obvious energy in second harmonic frequency compared to that of $0-160^{\circ}$ partial texture distribution, which indicates more obviously that misalignment between shaft journal and bearing bush occurred. 


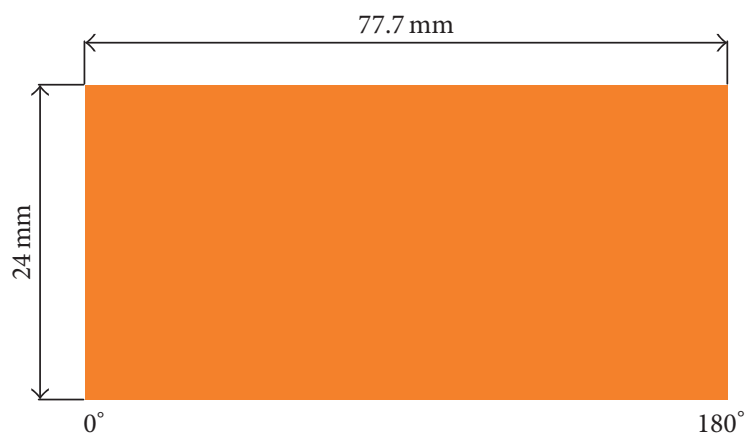

(a) Case 1 (no texture)

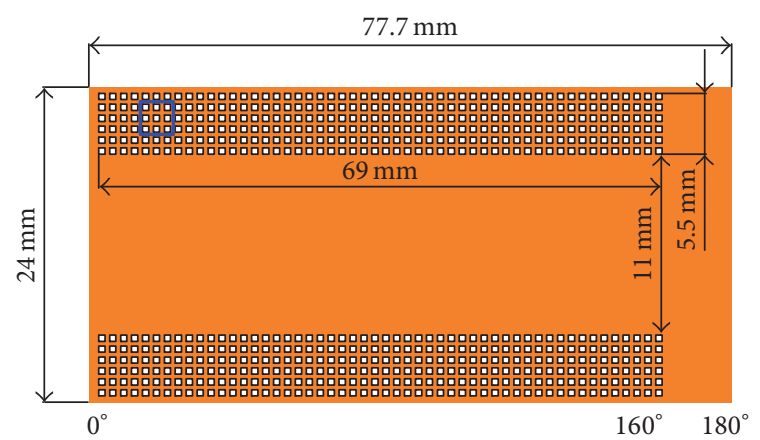

(c) Case $3\left(0-160^{\circ}\right.$ partial distribution)

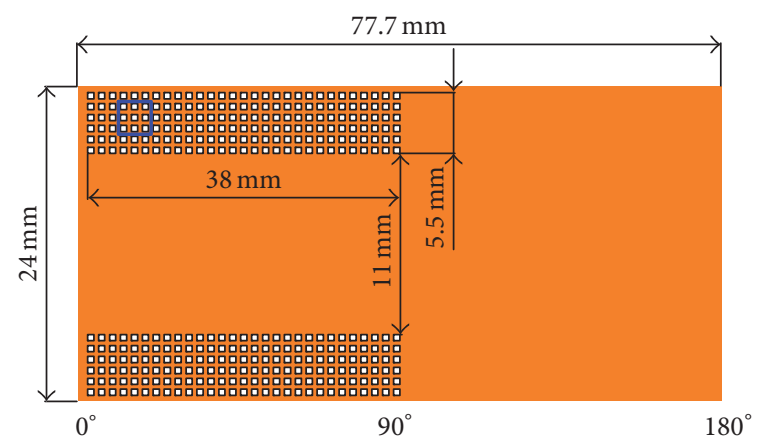

(b) Case $2\left(0-90^{\circ}\right.$ partial distribution)

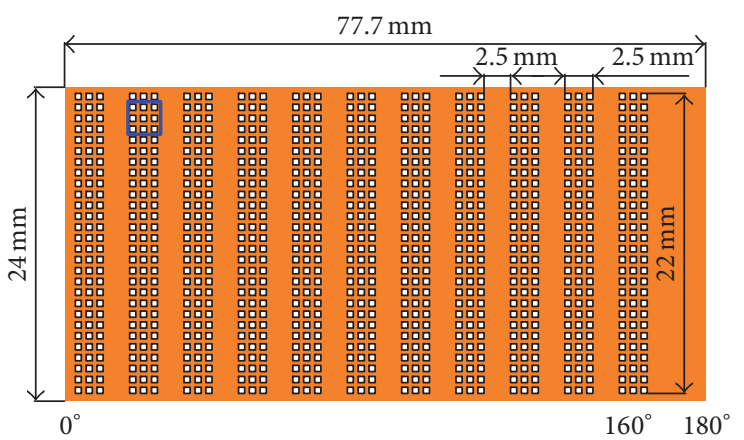

(d) Case $4\left(0-160^{\circ}\right.$ full distribution)

FIgURE 4: Textures configurations on the bearing surface for the 4 cases.

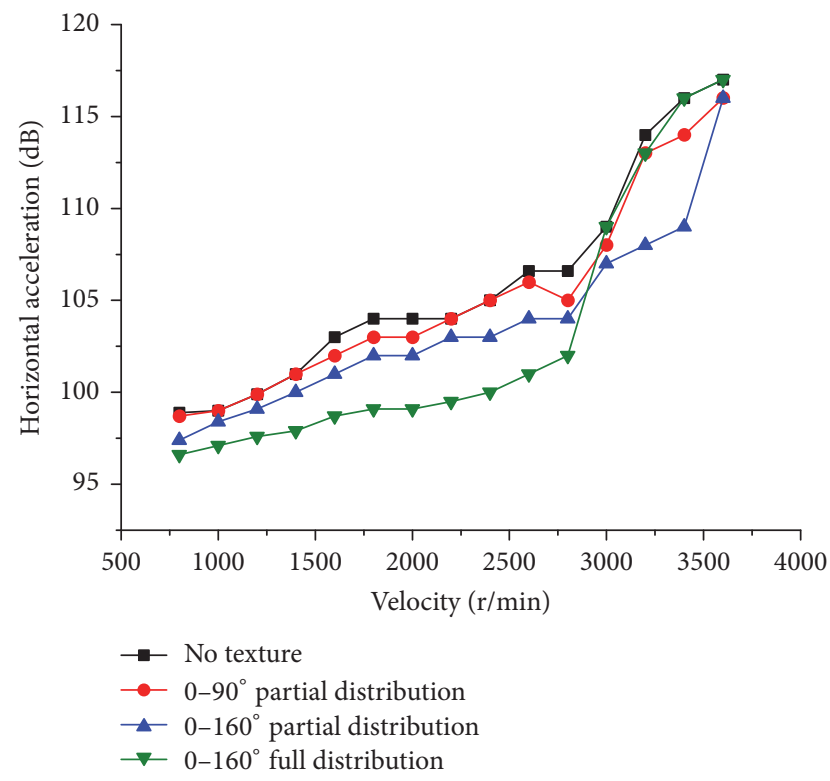

(a)

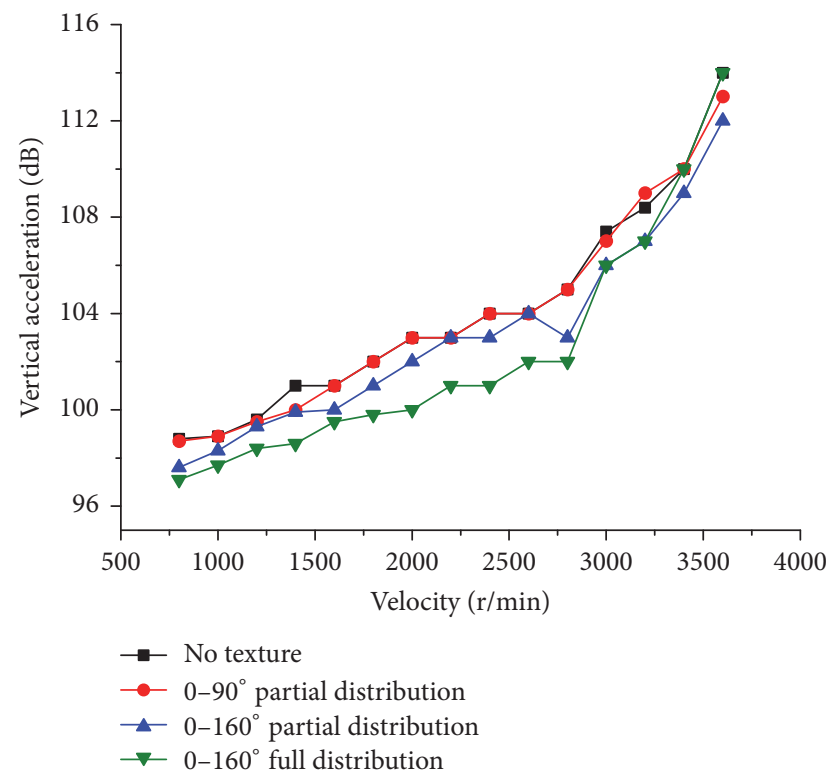

(b)

FIGURE 5: Acceleration amplitude of bearing housing: (a) horizontal direction; (b) vertical direction.

In practical engineering and field tests, shaft frequency amplitude of acceleration is usually used to analyze the vibration and stability of a rotor-bearing system. Different from the abovementioned Fourier spectrums which is described for amplitude of displacement, Figure 9 shows amplitude of vibration acceleration. It is worth noting that shaft frequency acceleration amplitude is different from total acceleration amplitude. Shaft frequency acceleration amplitude is an acceleration value of single frequency while total acceleration amplitude is a sum value, whose frequency is between $10 \mathrm{~Hz}$ and $8000 \mathrm{~Hz}$. It is found clearly that shaft frequency amplitude becomes greater with increasing 


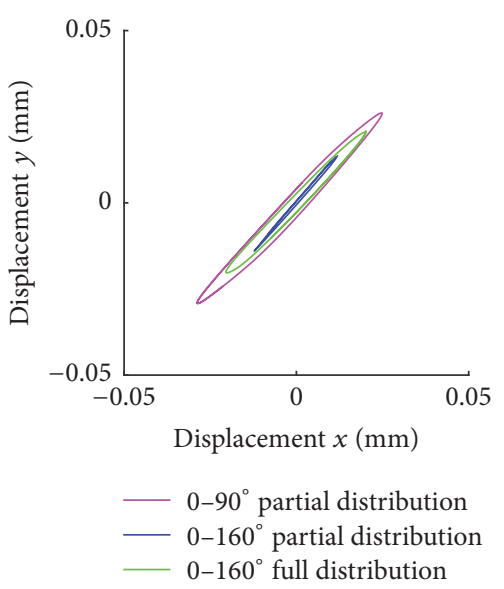

(a)

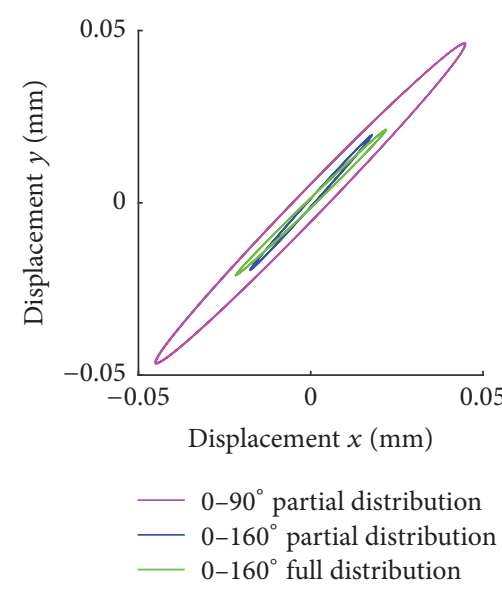

(b)

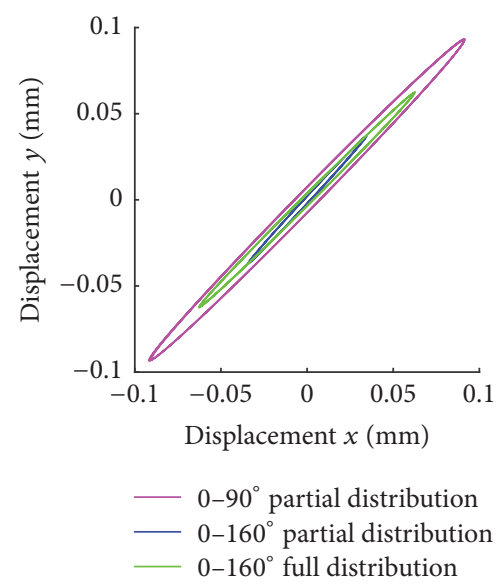

(c)

FIgURE 6: Shaft center orbits ( $y$ versus $x$ ): (a) $1000 \mathrm{r} / \mathrm{min}$; (b) $2800 \mathrm{r} / \mathrm{min}$; (c) $3600 \mathrm{r} / \mathrm{min}$.

rotating speed. However, there is no obvious difference in vibration acceleration amplitude among the three texture configurations at the same velocity. On the one hand, at low velocity (1000 rpm), amplitude in horizontal direction is lower than in vertical direction, owing to the impact of shock of lubricants flow coming from top of bearing seat. On the other hand, acceleration amplitude in horizontal direction is larger than in vertical direction, and bearing vibration caused by oil whirl has a more significant influence than lubricants shock at higher rotation speed (2800 rpm, $3600 \mathrm{rpm}$ ).

3.2. Discussion. Introduction of microdimples can change bearing stability and dynamic response, so the location of textured zone, relative textured area, area ratio, and density are necessary to be considered. The pattern of $0-160^{\circ}$ full distribution of laser texture shows the lowest acceleration among the four test cases in both of the horizontal and vertical directions when the rotation speed is lower than $2800 \mathrm{r} / \mathrm{m}$. When the shaft runs in low speed with small oil whirl energy, texture area ratio is more important to rotor stability. But when rotating speed increases over $2800 \mathrm{rpm}$, rotor kinetic energy becomes larger and therewith vibration acceleration. By this time, significance of texture location is greater. Through shaft center orbits, Fourier spectrums, and waterfall plots, it is found that the pattern of $0-160^{\circ}$ partial distribution of laser texture shows the best vibration control ability. The partially textured bearing in Case 3 can generate hydrodynamic lift, because texture is located in the two ends of the bearing where contact pressure is declined. Although bearing in Case 2 is also textured partially, the influence is limited and its texture location is where hydrodynamic pressure begins to form, so the bearing vibration is larger. Although shaft center eccentricity cannot be calculated here for bearing-neutral positions that were not accurately defined, relative shaft orbits of the textured bearings are available, which indirectly demonstrates that reasonable texture could change oil film pressure and result in more dense shaft orbits (see Figure 6). In fact, the nonlinear rotor-bearing system vibration is closely related to the oil film pressure [25], which can simultaneously reflect perturbed force. Dimple textures can store some oil film and indeed reduce oil film pressure perturbation, which can keep the operation of rotor-bearing system more stable. In this respect, surface texture could be a promising design as vibration absorption in journal bearings. By means of the same test rigs $[25,26]$, future work will be conducted, respectively, to investigate the dynamic characteristics of sliding bearings and thrust bearings with various textures; in addition, oil film pressure and temperature will be tested in that large sized bearings.

\section{Conclusions}

This paper is mainly for the experimental analysis of vibration and stability performance of laser-textured and smooth journal bearings, and the influence on rotor-bearing dynamic performance of different textures is studied according to the acceleration amplitude, shaft center orbits, frequency spectrum, and shaft frequency amplitude. In addition, waterfall plots are compared between the test bearings. Some conclusions can be obtained as follows:

(1) A test rig which can test vibration level is built in this paper. In addition, three kinds of textures are designed and processed by a laser machine.

(2) Surface-textured bearings show noticeable damping effect compared to nontextured bearings, textured bearings with $0-160^{\circ}$ full distribution reduce vibration prominently at the speed $0 \sim 2800 \mathrm{rpm}$, and a maximum acceleration amplitude difference of $5 \mathrm{~dB}$ has been found in horizontal direction. But when the rotation speed is greater than $2800 \mathrm{rpm}, 0-160^{\circ}$ partial texture distribution shows better performance than the other configurations.

(3) Shaft center orbit is measured to evaluate the stability of rotor-bearing system. The results show that 


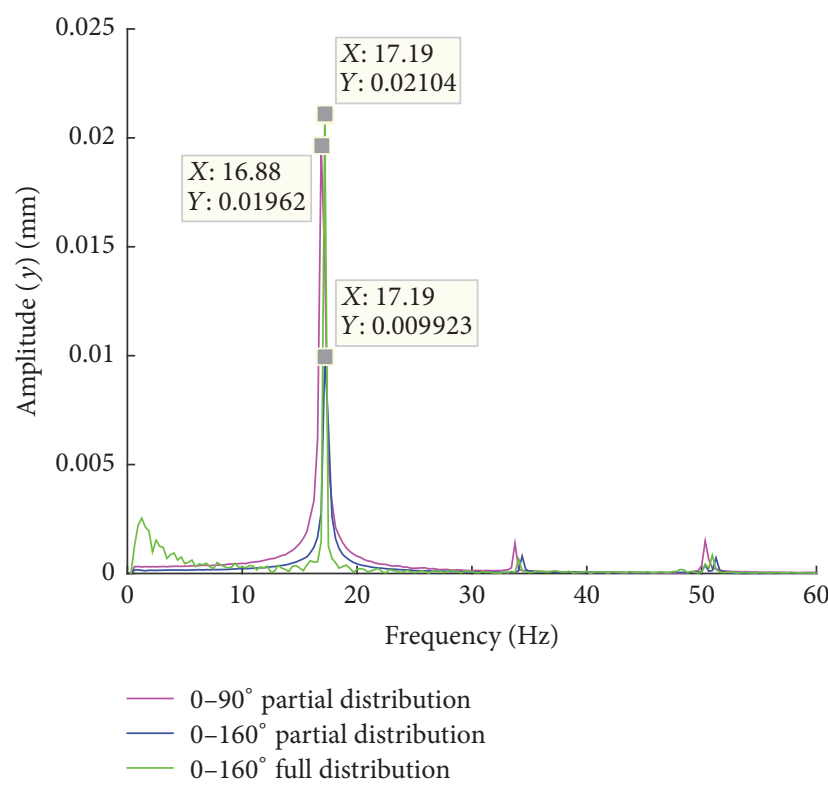

(a)

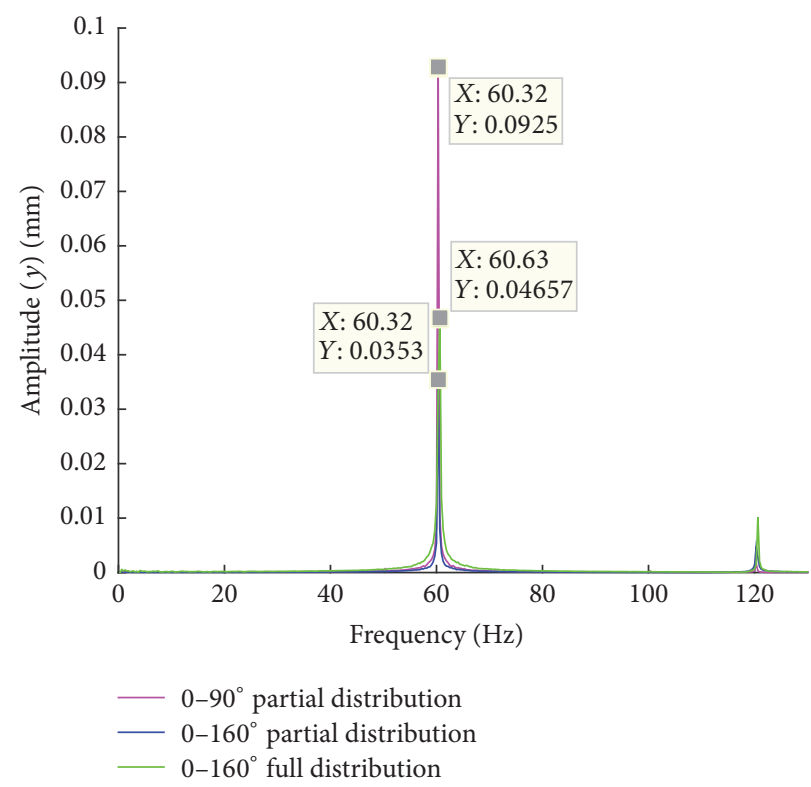

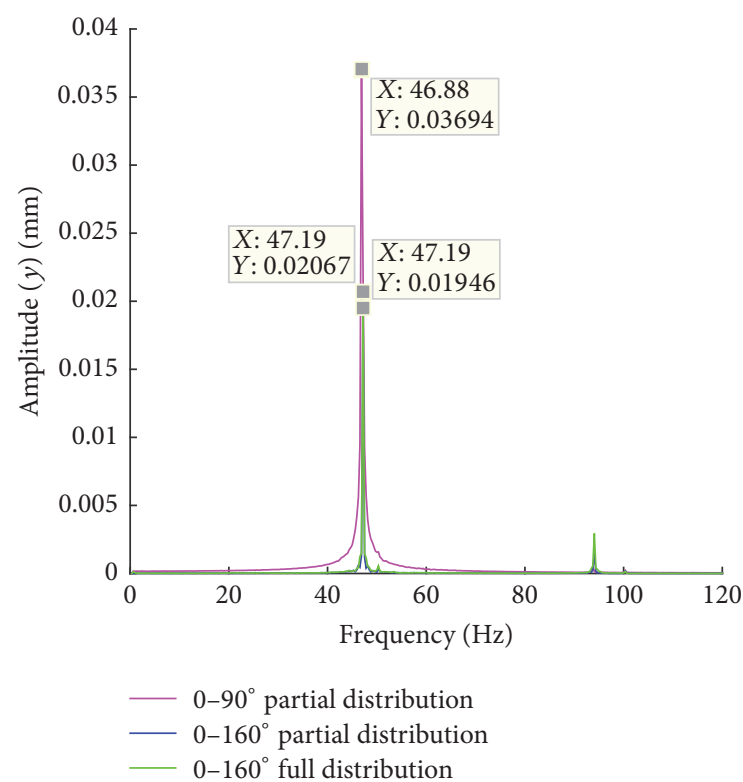

(b)

(c)

FIGURE 7: Comparison of spectrums at rotating speed: (a) $1000 \mathrm{r} / \mathrm{min}$; (b) $2800 \mathrm{r} / \mathrm{min}$; (c) $3600 \mathrm{r} / \mathrm{min}$.

shaft center orbit of the bearings with $0-160^{\circ}$ partially distributed textures tends to be more flat and smaller than the others, which indicates that it is less likely to produce destabilizing effect. Besides, frequency spectrum analysis is added to demonstrate the result.

(4) Waterfall plot is used in order analysis; it is found that displacement amplitude of journal bearing with $0-90^{\circ}$ partial texture distribution is almost the largest, which is nearly twice that of bearing with $0-160^{\circ}$ partial texture distribution. Besides, bearing of $0-160^{\circ}$ full texture distribution shows obvious energy in second harmonic frequency compared to that of $0-160^{\circ}$ partial texture distribution, which indicates more obviously that misalignment between shaft journal and bearing bush occurred.

(5) Shaft frequency amplitude of acceleration is discussed here. It is found that shaft frequency amplitude gradually becomes greater with increasing rotating speed. But there is no obvious difference in vibration acceleration amplitude among the three texture configurations at the same velocity. 


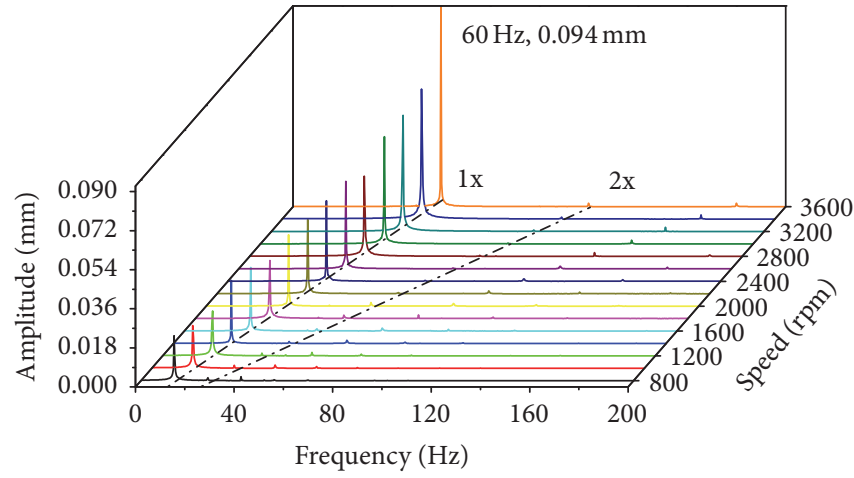

(a)

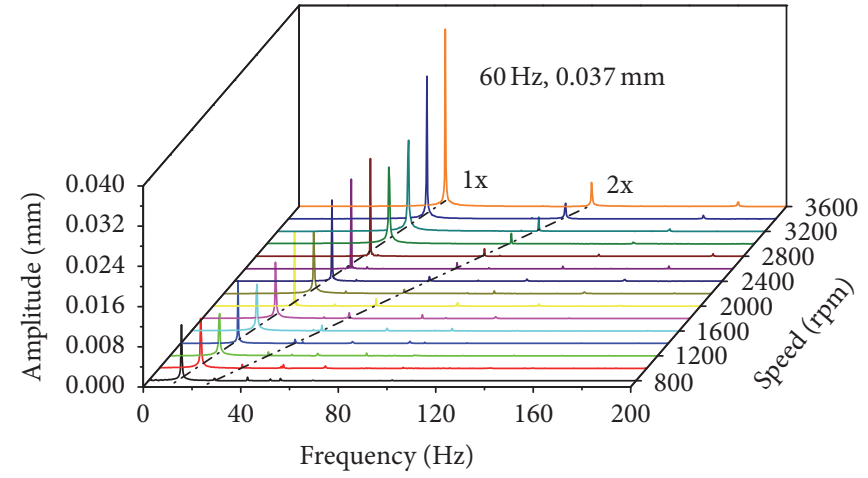

(b)

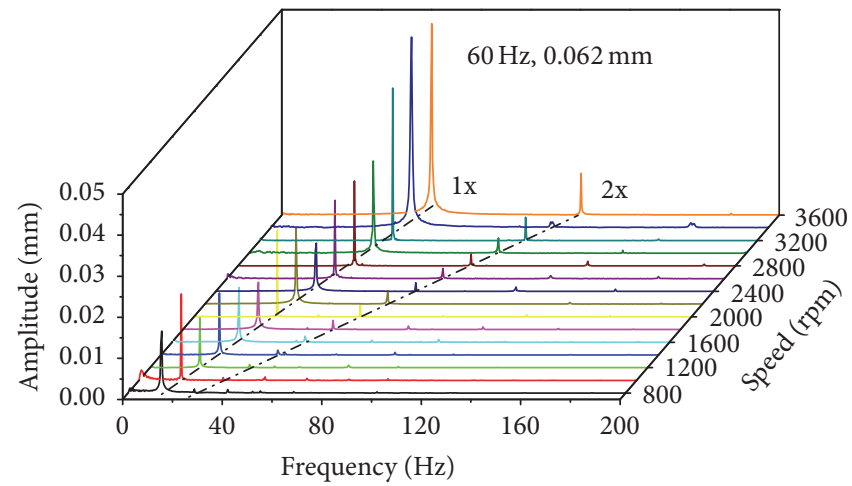

(c)

Figure 8: Comparison of waterfall plots: (a) 0-90 partial distribution; (b) 0-160 partial distribution; (c) $0-160^{\circ}$ full distribution.

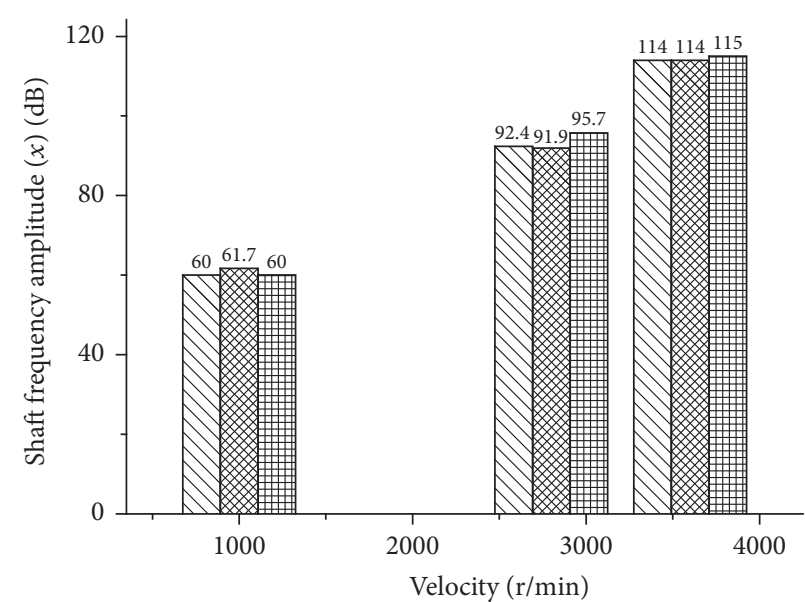

$\triangle 10-90^{\circ}$ partial distribution $0-160^{\circ}$ partial distribution 0-160 full distribution

(a)

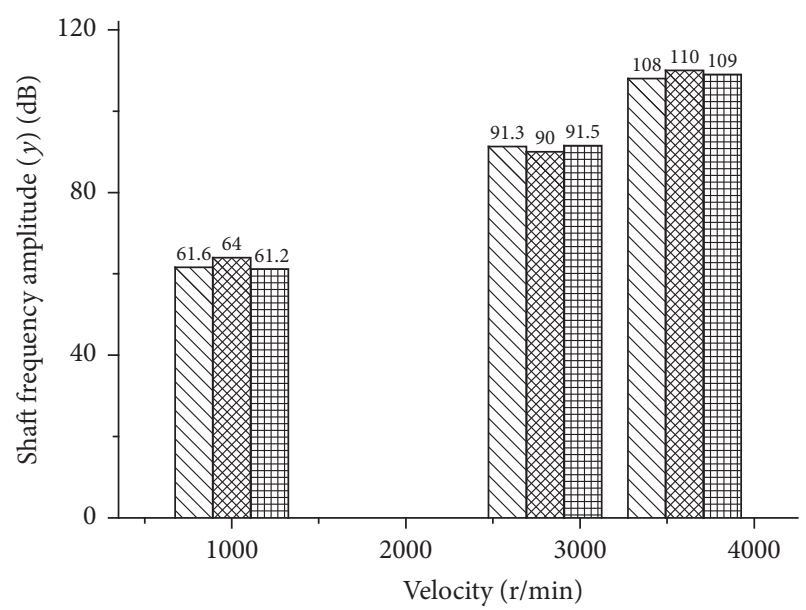

DV- $00^{\circ}$ partial distribution $0-160^{\circ}$ partial distribution 0-160 full distribution

(b)

FIGURE 9: Shaft frequency amplitude: (a) horizontal direction; (b) vertical direction. 


\section{Conflicts of Interest}

The authors declare that there are no conflicts of interest regarding the publication of this paper.

\section{Acknowledgments}

The authors acknowledge the support from Shanghai Science and Technology Committee (no. 14111103703) and Shanghai Key Laboratory of Intelligent Manufacturing and Robotics.

\section{References}

[1] D. Gropper, L. Wang, and T. J. Harvey, "Hydrodynamic lubrication of textured surfaces: a review of modeling techniques and key findings," Tribology International, vol. 94, pp. 509-529, 2016.

[2] Y. Kumada, "Performance of plain bearings with circumferential microgrooves@," Tribology Transactions, vol. 39, no. 1, pp. 81-86, 1996.

[3] F. Sahlin, S. B. Glavatskih, T. Almqvist, and R. Larsson, "Twodimensional CFD-analysis of micro-patterned surfaces in hydrodynamic lubrication," Journal of Tribology, vol. 127, no. 1, pp. 96-102, 2005.

[4] S. Cupillard, S. Glavatskih, and M. J. Cervantes, "Computational fluid dynamics analysis of a journal bearing with surface texturing," Proceedings of the Institution of Mechanical Engineers, Part J: Journal of Engineering Tribology, vol. 222, no. 2, pp. 97-107, 2008.

[5] H. Yong and R. Balendra, "CFD analysis on the lubrication behaviours of journal bearing with dimples," in Proceedings of the 2009 IEEE International Conference on Mechatronics and Automation (ICMA '09), pp. 1279-1284, August 2009.

[6] T. Nanbu, N. Ren, Y. Yasuda, D. Zhu, and Q. J. Wang, "Microtextures in concentrated conformal-contact lubrication: effects of texture bottom shape and surface relative motion," Tribology Letters, vol. 29, no. 3, pp. 241-252, 2008.

[7] C. Sinanoğlu, F. Nair, and M. B. Karamış, "Effects of shaft surface texture on journal bearing pressure distribution," Journal of Materials Processing Technology, vol. 168, no. 2, pp. 344-353, 2005.

[8] C. Sinanoğlu, "The analysis of the effects of surface texture on the capability of load carriage of journal bearings using neural network," Industrial Lubrication \& Tribology, vol. 57, no. 57, pp. 28-40, 2005.

[9] V. G. Marian, M. Kilian, and W. Scholz, "Theoretical and experimental analysis of a partially textured thrust bearing with square dimples," Proceedings of the Institution of Mechanical Engineers, Part J: Journal of Engineering Tribology, vol. 221, no. 7, pp. 771-778, 2007.

[10] V. G. Marian, D. Gabriel, G. Knoll, and S. Filippone, "Theoretical and experimental analysis of a laser textured thrust bearing," Tribology Letters, vol. 44, no. 3, pp. 335-343, 2011.

[11] R. Ausas, P. Ragot, J. Leiva, M. Jai, G. Bayada, and G. C. Buscaglia, "The impact of the cavitation model in the analysis of microtextured lubricated journal bearings," Journal of Tribology, vol. 129, no. 4, pp. 868-875, 2007.

[12] F. M. Meng and T. Yang, "Preliminary study on mechanism of cavitation in lubricant of textured sliding bearing," Proceedings of the Institution of Mechanical Engineers, Part J: Journal of Engineering Tribology, vol. 227, no. 7, pp. 695-708, 2013.
[13] V. Brizmer and Y. Kligerman, "A laser surface textured journal bearing," Journal of Tribology, vol. 134, no. 3, Article ID 031702, 2012.

[14] V. Brizmer, Y. Kligerman, and I. Etsion, "A laser surface textured parallel thrust bearing," Tribology Transactions, vol. 46, no. 3, pp. 397-403, 2003.

[15] N. Tala-Ighil, M. Fillon, and P. Maspeyrot, "Effect of textured area on the performances of a hydrodynamic journal bearing," Tribology International, vol. 44, no. 3, pp. 211-219, 2011.

[16] T. Ibatan, M. S. Uddin, and M. A. K. Chowdhury, "Recent development on surface texturing in enhancing tribological performance of bearing sliders," Surface \& Coatings Technology, vol. 272, pp. 102-120, 2015.

[17] I. Etsion, "Improving tribological performance of mechanical components by laser surface texturing," Tribology Letters, vol. 17, no. 4, pp. 733-737, 2004.

[18] K. Tønder, "Hydrodynamic effects of tailored inlet roughnesses: extended theory," Tribology International, vol. 37, no. 2, pp. 137142, 2004.

[19] T. S. R. Ganji and S. K. Kakoty, "Effect of cylindrical texture on dynamic characteristics of journal bearing," International Journal of Recent Advances in Mechanical Engineering (IJMECH), vol. 3, no. 4, 2014.

[20] A. Dadouche, M. J. Conlon, W. Dmochowski, W. Koszela, L. Galda, and P. Pawlus, "Effect of surface texturing on the steadystate properties and dynamic coefficients of a plain journal bearing: Experimental study," in Proceedings of the ASME 2011 Turbo Expo: Turbine Technical Conference and Exposition (GT '11), pp. 695-704, American Society of Mechanical Engineers, June 2011.

[21] A. Dadouche and M. J. Conlon, "Operational performance of textured journal bearings lubricated with a contaminated fluid," Tribology International, vol. 93, pp. 377-389, 2016.

[22] R. Zhan, X. Xiong, and X. Wang, "Integral centering spring squeeze film damper on the vibration stability of journal bearing-rotor system modeling and experimental validation," in Proceedings of 14th EDF/Pprime Workshop: 'Influence of Design and Materials on Journal and Thrust Bearing Performance, Futuroscope, 2015.

[23] F. Y.Zeidan and B. S. Herbage, "Fluid film bearing fundamentals and failure analysis," in Proceedings of the 20th Turbo Machinery Symposium, pp. 161-186, 1991.

[24] L. Maurice and M. L. Adams Jr., Rotating Machinery-From Analysis to Troubleshooting, Marcel Dekker, New York, NY, USA, 2001.

[25] J. Shen, X. Xiong, G. Li, X. Wang, Z. Hua, and Z. Nie, "Experimental analysis of dynamic oil film pressure of tilting-pad journal bearings," Tribology Letters, vol. 63, no. 3, pp. 1-9, 2016.

[26] Z. Nie, G. Li, X. Wang, Y. Jiao, Z. Hua, and G. Yu, "Dynamic experimental research of PTFE-Faced Pad Thrust Bearings," Tribology Letters, vol. 62, no. 1, pp. 1-8, 2016. 


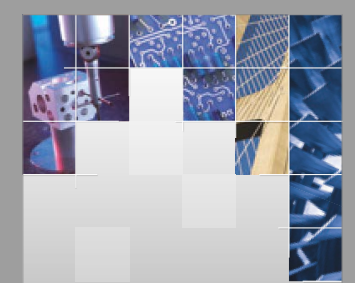

\section{Enfincering}
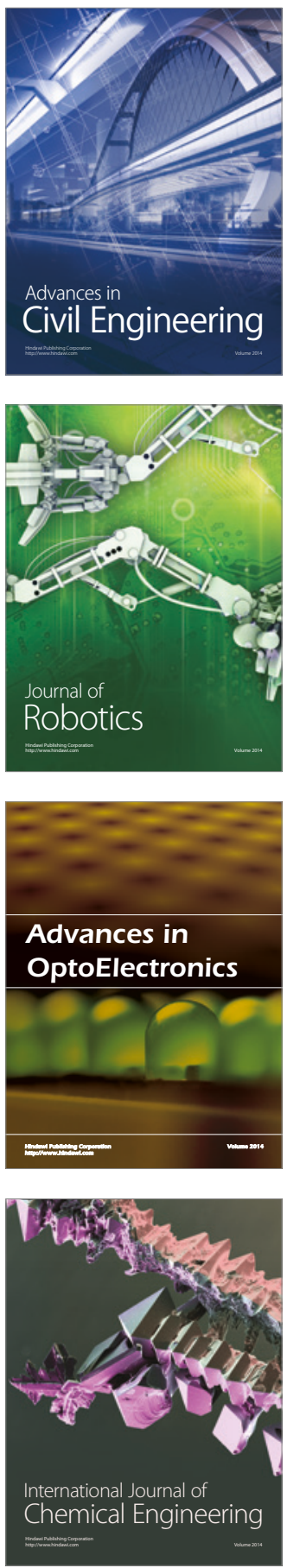

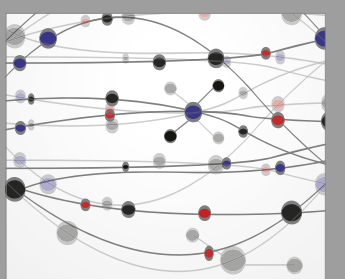

The Scientific World Journal

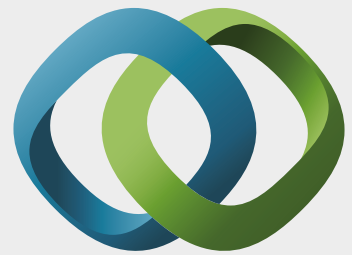

\section{Hindawi}

Submit your manuscripts at

https://www.hindawi.com
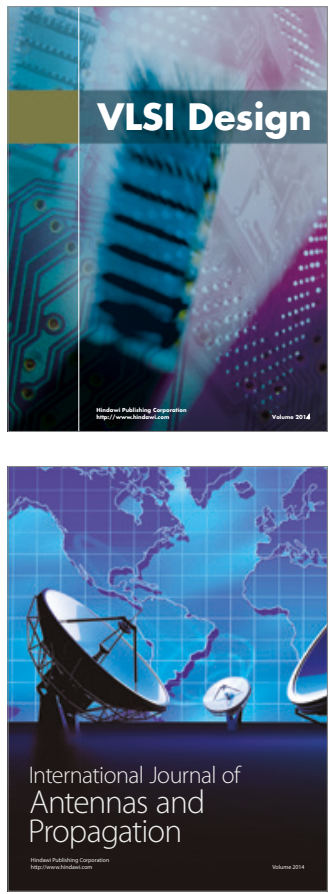

\section{Rotating}

Machinery
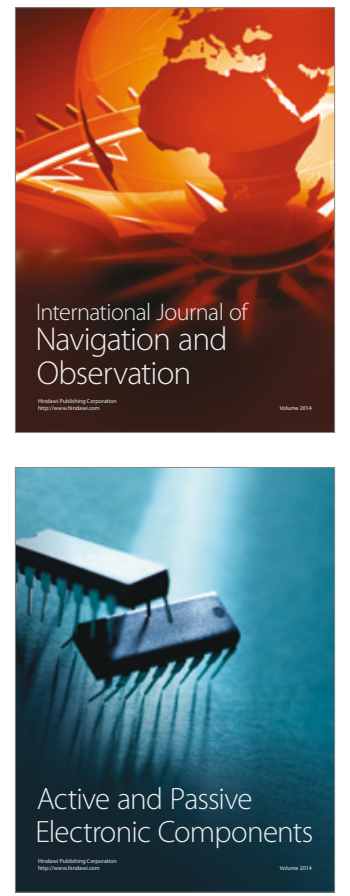
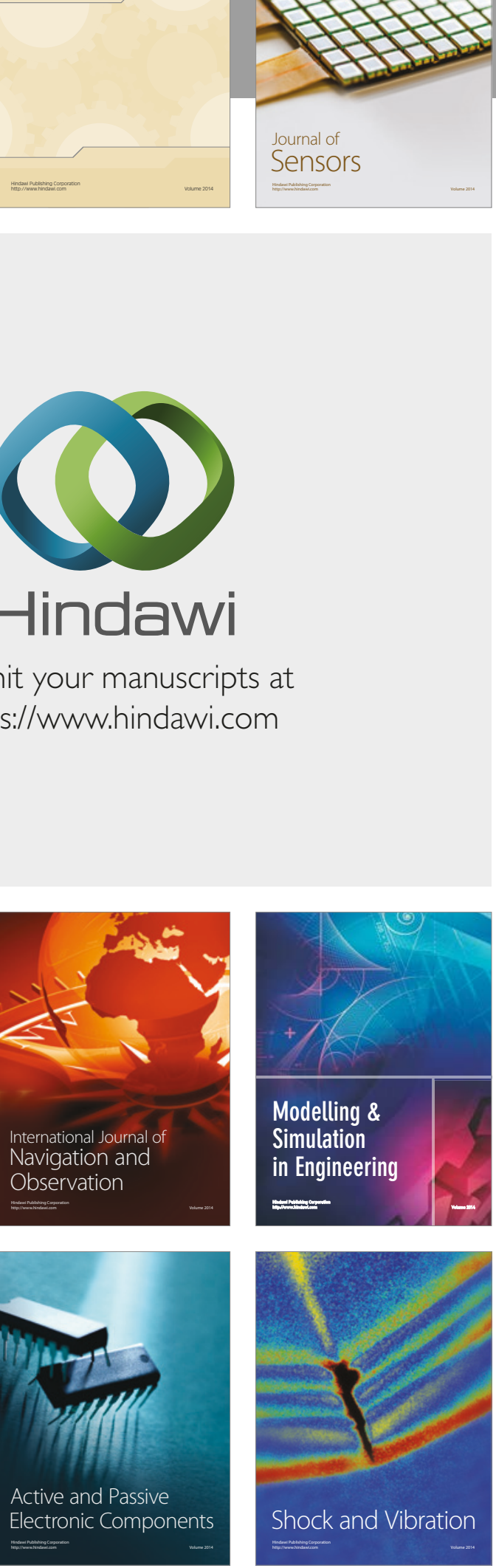
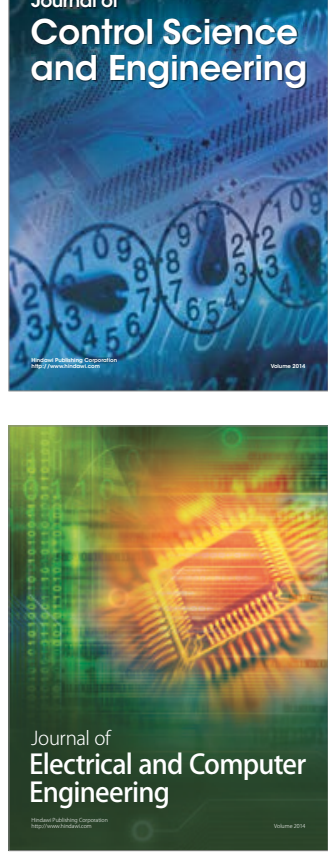

Distributed

Journal of

Control Science

and Engineering
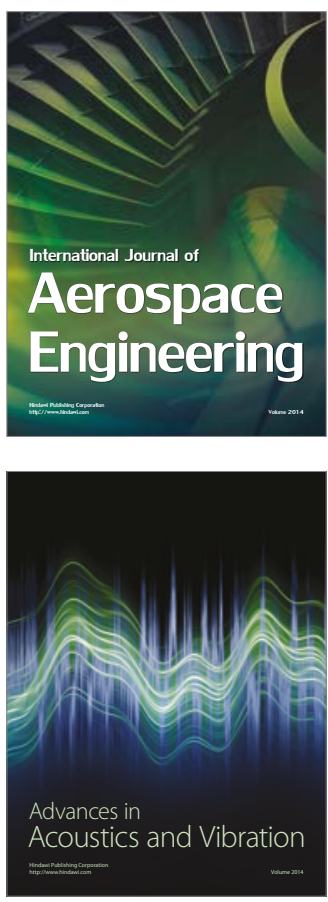

Sensor Networks 